Usage, Usability, and Utility of 3D City Models, 01002 (2012)

DOI: $10.1051 / 3 \mathrm{u} 3 \mathrm{~d} / 201201002$

(C) Owned by the authors, published by EDP Sciences, 2012

\title{
Efficient visualization of urban spaces
}

\author{
A.E. Stamps III \\ Institute of Environmental Quality, 290 Rutledge Street, San Francisco, California 94110, USA
}

\begin{abstract}
This chapter presents a new method for calculating efficiency and applies that method to the issues of selecting simulation media and evaluating the contextual fit of new buildings in urban spaces. The new method is called "meta-analysis". A meta-analytic review of 967 environments indicated that static color simulations are the most efficient media for visualizing urban spaces. For contextual fit, four original experiments are reported on how strongly five factors influence visual appeal of a street: architectural style, trees, height of a new building relative to the heights of existing buildings, setting back a third story, and distance. A meta-analysis of these four experiments and previous findings, covering 461 environments, indicated that architectural style, trees, and height had effects strong enough to warrant implementation, but the effects of setting back third stories and distance were too small to warrant implementation.
\end{abstract}

\section{INTRODUCTION}

The topic of this chapter is how to visualize, efficiently, urban spaces. The approach of this chapter is as follows: First, the concept of "efficient" is re-formulated in terms of quality control as measured with the statistical method of meta-analysis. Second, meta-analysis is applied to the specific topic of choosing simulation media on the basis of efficiency. Third, the concept of "urban spaces" is considered under the specific topic of "contextual design principles". Four original experiments on contextual design principles are reported, and meta-analysis is applied to the issue of selecting the most efficient principles. We begin with the concept of "efficiency".

\section{EFFICIENCY}

In this chapter, the concept of "efficiency" is considered from the point of view of "quality control". Quality control has been a topic of interest for millennia. Examples from ancient China, ancient Israel, Greek temples, Scandinavian shipbuilding, building cathedrals, and other historical examples are given in [1]. Based on the seminal book by Shewhart [2], quality control has been widely implemented to monitor and control commercial processes [3] and for policy guidance for government and education as well [4]. Key concepts in quality control include the following: (a) Formalizing "quality" into some criterion that can be used to categorize things in terms of "less than", "same as" or "more than". The latter conditions enable the criterion to be used as a measurement [5]. The usual label for this concept is "measure of performance". (b) Distinguishing factors by how strongly they influence the measure of performance. The relevant techniques are the sampling [6] and the design of experiments [7]. (c) Focus attention on the factors with the largest effect on the measure of performance. In informal terms, this means work on the things with the biggest effects first. (d) Eliminate waste. In practical terms, this means don't waste time on things that have been shown to fail or on repeating things that

\footnotetext{
${ }^{a}$ Institute0fEnvironmentalQuality@comcast.net; http://www. Institute0fEnvironmentalQuality.org
}

This is an Open Access article distributed under the terms of the Creative Commons Attribution License 2.0, which permits unrestricted use, distribution, and reproduction in any medium, provided the original work is properly cited. 
Usage, Usability, and Utility of 3D City Models

Table 1. Hypothetical data for a meta-analysis.

\begin{tabular}{c|cc|rrrrrr}
\hline \multirow{2}{*}{ Exp } & \multicolumn{7}{|c}{ Findings } \\
\cline { 2 - 9 } & \multicolumn{7}{|c|}{ Individual } & \multicolumn{7}{c}{ Collective } \\
\cline { 2 - 9 } & $r$ & $n$ & $\hat{r}$ & $\Sigma \mathrm{n}$ & $.05 \mathrm{ci}$ & $\mathrm{n}_{\text {over }}$ & $\chi^{2}$ & $\alpha$ \\
\hline \hline 1 & .3 & 20 & .3 & 20 & $-.16, .66$ & -24 & 0.00 & - \\
2 & .3 & 30 & .3 & 50 & $.02, .53$ & 14 & 0.00 & - \\
3 & .8 & 20 & .48 & 70 & $.28, .44$ & 267 & 7.63 & .03 \\
4 & .8 & 30 & .61 & 100 & $.46, .71$ & 1124 & 13.63 & .002 \\
\hline
\end{tabular}

are already firmly established. Concentrate resources on topics that are most likely to make the largest improvement in the knowledge regarding the factors of interest.

More recently (1993) statistical methods have been applied to the issue of translating scientific findings into policy guidance. These translations are done by the Cochrane Collaboration [8]. The Cochran Collaboration focuses on medicine, and the overall approach is as follows:

"How do you know if one treatment will work better than another, or if it will do more harm than good? Cochrane Reviews are systematic reviews of primary research in human health care and health policy, and are internationally recognized as the highest standard in evidence-based health care. They investigate the effects of interventions for prevention, treatment and rehabilitation. They also assess the accuracy of a diagnostic test for a given condition in a specific patient group and setting. They are published online in The Cochrane Library." [9]

In other words, the Cochrane approach puts the evidence into "evidence-based decision making" [10]. To date this approach has been applied to over 5000 medical interventions [11]. Details on the Cochrane method are given in [12]. There are two stages in the Cochrane method. The first stage is the collection of data in an individual experiment. Experiments are done following explicit scientific standards to ensure validity and results are reported as "effect sizes" [13]. An effect size is a statistic with a special quality: its distribution over multiple instances is known [14]. Consequently statistical conclusions can be made over many studies instead of being limited to one study. Meta-analysis is the second phase of the Cochrane method.

It takes very little imagination to realize that (a) the Cochrane method can be applied to issues other than medicine, and (b) meta-analysis can be used to pick the most effective means for achieving desired ends and so constitutes a very useful quality control technique. Accordingly it is useful to have a solid understanding of meta-analysis. There are many references on how to do and interpret meta-analysis but, over the years, I have found the simple formulation in [15] to be more than adequate. Table 1 shows the results obtainable with this simple formulation.

This table lists findings from four individual experiments (Exp 1, 2, 3, and 4). The effect sizes for individual findings are reported as correlations $(r)$. Each correlation is calculated over a sample of $n$ units. For studies regarding stimulus variables (such as urban design principles) $n$ will be the number of stimuli. Now here is where meta-analysis differs from traditional reviews. In a traditional review, someone would look at the four individual results, note that they seem to differ, and suggest that more work needs to be done. In meta-analysis, a collective finding $(\hat{r})$ is calculated. Because there are now more units under inquiry (20 after Exp 1, 50 after Exp 2, etc.), the collective findings are statistically more powerful than any individual finding. This enables detection of more subtle results than are obtainable in a single experiment. Additionally the collective confidence interval (.05 ci) can be calculated. If this interval excludes 0.0 , then the collective finding has achieved the conventional criterion of " $p<.05$ ". If the ci does include 0.0, then the collective finding has not achieved the " $p<.05$ " level. This equivalence enables translation from the meta-analytic paradigm back to the 
" $p$ level" paradigm. The next column $\left(\mathrm{n}_{\text {over }}\right)$ is the size $(n)$ of a new study that would change the collective significance from " $p<.05$ to " $p>.05$ " or vice-versa. For example, if $\mathrm{n}_{\text {over }}$ is negative, then the collective finding is not yet significant and it would take a new findings with $n=24$ and a correlation equal to the current collective finding $(r=.3$ ) to establish the claim at the " $p<.05$ " level. In practice, a negative $\mathrm{n}_{\mathrm{over}}$ indicates the amount of additional work needed to up-grade a not-yet-significant finding to a significant finding. In terms of quality control, this means one can use $\mathrm{n}_{\text {over }}$ to select the most promising topic for future research. If one topic would require a new $n$ of 20 , while another topic would require a new $n$ of 500, and one had the resources to obtain a new $n$ of 30, then efficiency would suggest working on the first topic. The first two rows of Table 1 illustrate this point. After Experiment 1, the collective ci includes 0.00 and the $\mathrm{n}_{\text {over }}=-24$. This $\mathrm{n}_{\text {over }}$ means a new experiment with $n>24$ and $r=.3$ would be needed to establish the collective claim at the " $p<.05$ level". Experiment 2, with $n=30$ and $r=.3$ does precisely that, and so the revised collective finding becomes significant. The new $\mathrm{n}_{\text {over }}$ is now positive at 14. A positive $\mathrm{n}_{\text {over }}$ is the $n$, with an individual finding of $r=0.00$, that would be needed to impeach a collective finding at the " $p<.05$ " level. This value can be useful in discourses about findings. If a claim (the "thesis") is based on effect-size evidence, then the evidence provided to support an objection (the "antithesis") can be combined with the evidence provided to support a claim and the resulting collective finding will combine the thesis and antithesis into a single statistical synthesis. On the other hand, if the antithesis is based on conjecture ("Yes, but there might be some unreported data somewhere that would change the conclusions."), then $\mathrm{n}_{\text {over }}$ would indicate just how much more missing data would be needed to substantiate an objection. In this use, $\mathrm{n}_{\text {over }}$ serves as an index of plausibility. If $\mathrm{n}_{\text {over }}$ is small, then an objection based on conjecture is plausible, but if $\mathrm{n}_{\text {over }}$ is large, then the objection would be based on grasping at straws. Thus, in Table 1, an objection made after Experiment 2 would need an $n$ of 14, but, after Experiment 4, the burden of proof for an objection would be $n=1124$.

The last two columns in Table 1 indicate the heterogeneity of findings. This information is particularly useful when the overall claim is solid but there might be differences among the various individual findings that would merit subdivision of the data. For example, it is clear that Experiments 1 and $2\left(r^{\prime} s=.3\right.$ and .3$)$ produced different results than Experiments 3 and 4 ( $r^{\prime} s=.8$ and .8$)$. The statistic for heterogeneity $\left(\chi^{2}\right.$ on $d f=$ number of experiments -1 ) increases from 0.0 (no heterogeneity at all) to 7.63 and then to 13.63 . The latter two $\chi^{2}$ are significant, indicating that there is more than one story in this dataset. This hypothesis can be tested directly with the meta-analytic version of regression on the contrast between Experiments 1 and 2 and Experiments 3 and 4 . The result is that, yes, there is a difference between the two groups of experiments $(Q=13.70, \alpha=1 \mathrm{e}-4)$. It only needs to be discovered what was the difference between the two groups of experiments that produced this heterogeneity? Suppose, for instance, that the claim was about the amount of effort needed to throw a ball. If that were the only information available (as might be reported in traditional reviews, for example), it would not be possible to explain the differences. However, with meta-analysis, one can revisit the original data. For example, if Experiments 1 and 2 used beach balls but Experiments 3 and 4 used shot-puts, then the reason why the results from the two groups of experiments differ would become perfectly clear.

Table 1 lists hypothetical data. Tables 2 and 3 list actual data for the claim that choice of scaling method has such a small effect on results that, in the interest of efficiency, the simplest scaling method should be used. Table 2 lists eight individual studies, the $r$ 's and $n$ ' $s$, and the citation. Table 2 also lists a hypothetical new study with a hypothetical $r=.5$ and a hypothetical $n=24$. This entry shows how meta-analysis can be used to estimate the effect a prospective new study would have on the collective finding. If the estimated effect would be large, then the result would constitute a substantial addition to the literature and would have a better chance of being published than if the result would make little or no difference to the literature. Obviously this type of information would greatly improve the efficiency of a research program. Suppose, for instance, that there was some reason for claiming that some scaling method correlated at only $r=.5$ with the other methods. Further suppose that budget considerations 
Usage, Usability, and Utility of 3D City Models

Table 2. Sources for meta-analysis of scaling methods.

\begin{tabular}{|l|l|c|r|c|}
\hline Exp & Methods & $\mathrm{r}$ & $\mathrm{n}$ & Citation \\
\hline 1 & Ratings and rank orders & .92 & 8 & {$[16]$} \\
2 & Ratings and qsort & .89 & 8 & {$[16]$} \\
3 & Ranks and qsort & .97 & 8 & {$[16]$} \\
4 & Ranks and ranks of ratings & .89 & 12 & {$[17]$} \\
5 & Ranks v. place on table & .97 & 21 & {$[18]$} \\
6 & Raw score v. comparative judgment & .99 & 900 & {$[19]$} \\
7 & Raw score v. true score & .93 & 80 & {$[19]$} \\
8 & Raw score v. signal detection & .99 & 113 & {$[19]$} \\
9 & Hypothetical new experiment & .50 & 24 & N/A \\
\hline
\end{tabular}

Table 3. Meta-analytic summary of scaling methods.

\begin{tabular}{lccccccc}
\hline Factors & Sources* & $\hat{r}$ & $\Sigma \mathrm{n}$ & $.05 \mathrm{ci}$ & $\mathrm{n}_{\text {over }}$ & $\chi^{2}$ & $\alpha$ \\
\hline $\begin{array}{l}\text { Scaling methods before } \\
\text { new experiment }\end{array}$ & $1-8$ & .987 & 1150 & $.98, .98$ & $>100 \mathrm{~K}$ & 97.8 & $2 \mathrm{e}-18$ \\
$\begin{array}{l}\text { Scaling methods after hypothetical } \\
\text { new experiment }\end{array}$ & $1-9$ & .986 & 1174 & $.98, .98$ & $>100 \mathrm{~K}$ & 231 & $2 \mathrm{e}-46$ \\
\hline
\end{tabular}

* Indicates rows in Table 2.

limited the size of a prospective new study to $n=24$. If the new study were successful, what would the impact on the collective body of knowledge be? The meta-analytic approach to this question is to run one analysis on Experiments 1 through 8 and then run a second analysis that also included the prospective experiment. The differences between collective result obtained from experiments done before or after the prospect new experiment would provide the guidance on whether the new experiment would be worth doing.

The before and after meta-analysis is shown in Table 3. Before the new experiment, the collective effect size was $r=.987$ with a ci of $.98, .98$. After the new experiment, if it worked at all, the collective effect size would be $r=.987$ and the ci would be $.98, .98$. Would the new data change the collective knowledge? Would the new data be publishable? Probably not and probably not. Efficiency would strongly suggest finding another topic for future work. This line of work is done. It's time to move on.

\subsection{Summary of section}

The concept of efficiency is formalized in terms of the statistical method of meta-analysis. Examples of both hypothetical and real data are given to show how meta-analysis can be used to inform evidencebased decision-making and for making choices based on how efficient they would be. For readers who need more numbers, all the calculations used in this chapter are given in [15]. Applications to topics in environmental research are given in [20]. The application to efficient research is given in [8, 12], and the application to peer review is given in $[21,22]$. 
Table 4. Meta-analytic summary of simulation methods.

\begin{tabular}{|c|c|c|c|c|c|c|c|c|}
\hline Exp & Factors & Sources* & $\hat{r}$ & $\Sigma \mathrm{n}$ & $.05 \mathrm{ci}$ & $\mathrm{n}_{\text {over }}$ & $\chi^{2}$ & $\alpha$ \\
\hline 1 & $\begin{array}{l}\text { On-site vs. static color } \\
(2000)^{* *}\end{array}$ & $3,15,21,26$ & .83 & 185 & $.79, .87$ & 12,486 & 9.15 & .001 \\
\hline 2 & Slide vs. digitized slide & $4,5,6,26$ & .84 & 309 & $.80, .87$ & 35,880 & 18.0 & $1 e-5$ \\
\hline 3 & $\begin{array}{l}\text { On-site vs. black \& white } \\
\text { sketch }\end{array}$ & 16,22 & .56 & 18 & $.12, .81$ & 15 & 0.7 & .33 \\
\hline 4 & $\begin{array}{l}\text { Static color vs. black \& white } \\
\text { sketch }\end{array}$ & 19,23 & .41 & 18 & $-.07, .73$ & -6 & 0.97 & .25 \\
\hline 5 & $\begin{array}{l}\text { On-site static color } \\
(2010)^{* * *}\end{array}$ & 32 & .87 & 205 & $.84, .90$ & 28,252 & 32.0 & .01 \\
\hline 6 & $\begin{array}{l}\text { On-site vs. dynamic } \\
\text { simulations }\end{array}$ & 33 & .83 & 171 & $.78, .87$ & 15,007 & 35.2 & $2 e-5$ \\
\hline 7 & $\begin{array}{l}\text { Static color vs. dynamic } \\
\text { simulations }\end{array}$ & 34 & .82 & 135 & $.76, .86$ & 8,446 & 6.1 & .41 \\
\hline
\end{tabular}

* Indicates citation or rows in Table A.1.

** Review done in 2000.

*** Review done in 2010.

\section{SIMULATION}

Efficiency is important in environmental design because design is typically an iterative process which cycles between ideas and how environments that express those ideas will appear. It is not at all unusual to go through dozens or hundreds of iterations, so, if the simulation medium is too cumbersome, it won't be used. For example, Mullins [23] described an international architectural competition in Denmark in which entrants were required to submit 3D visualizations. It was noted that this case study provided indications of what may be the standard submission requirements in future presentations to public competition juries. Another example is a local planning process that requires design review for over 200 hundred projects per year [24]. The main review criterion is contextual fit [25]. Implementation of the contextual fit criterion requires visual simulations. Is it the case that the dynamic simulations required for the Danish concert hall are necessary to evaluate contextual fit of houses at a rate of 200 per year, or will simpler simulation protocols suffice?

Application of the meta-analytic paradigm to the question of simulation efficiency produced Table 4. The list of sources for Table 4 is too long to show in the text, so those sources re listed in Table A.1 in the Appendix. The top five rows of Table 4 summarize a literature review done on simulations in 2000 [26]. The bottom 3 rows of Table 4 summarize a literature review done in 2010 [27]. That review covered 6323 participants and 967 environments. Responses included ratings of pleasure, naturalness, familiarity, order, inertia, arousal, threat, disliking, liking of the environment, nice area to walk through, good area to live in, appreciation of the area, visual appeal, evaluation, ambience, arousal, privacy, security, pleasant, interest, comfortable, excited, playful, water, built, water flow, sun, sound, strolling, resting, talking, observing, preference, and spaciousness. Some studies reporting findings for physical properties such as distance, height, width, and length. Other studies reported behaviors such as path choice and exploration.

Using the methods described in Section 1, the following inferences can be made from Table 4. The process of presenting images on a computer screen instead of with slides produced virtually the same responses ( $r$ 's of .84 vs. .83, ci's of $.79, .87$ and $.80, .87$ ). The formal test of the contrast between these two types of simulations was not significant $\left(\chi^{2}(1)=0.14, \alpha=.94\right)$. It made no difference whether a 
scene was shown as a slide or on a computer screen. On the other hand, responses were different if scenes were shown as static or black and white images ( $r$ 's of.83 and $.41, \chi^{2}(1)=7.85, \alpha=.003$ ), so color really is necessary for validity. The difference between static color as reviewed in 2000 and as reviewed in 2010 was also statistically negligible ( $r$ 's of .83 vs. $.87,\left(\chi^{2}(1)=2.01, \alpha=.10\right)$, indicating that the studies done on this topic between 2000 and 2012 were a waste of resources and so were inefficient. For the contrast between static and dynamic simulations, the results were $r$ ' $s$ of .87 and .83. This difference was also statistically negligible $\left(\chi^{2}(1)=1.92, \alpha=.10\right)$, indicating that the extra expense associated with dynamic simulations is also probably an inefficient use of resources. Because of these findings, static color simulations were used in the original experiments on urban design that are reported in Section 4.

\subsection{Summary of section}

Meta-analysis can be used to evaluate the effectiveness of various simulation media. For representing environments, color matters. Up-grading from static to dynamic simulations has no detectable effect on responses, indicating that, for simulating environments, static color images will be the more efficient form of simulation.

\section{URBAN SPACES}

In this chapter, the concept of "urban spaces" is considered under the specific topic of "contextual design principles". The central concept of contextual design is "contextual fit". Contextual fit is an important criterion for evaluating building projects in the United States [28], as well as in other countries, including the UK [29], France [30], Germany [31], Sweden [32], Italy [33], the Netherlands [34], Spain [35], and Japan [36]. Contextual fit is nearly always evaluated in terms of how well a project would look in its physical context [28], which implies that visual simulations are an integral part of contextual design review. There are literally hundreds of design features that have been regulated as contextual design principles [37]. Some of those principles have been tested scientifically. This section describes four such experiments on five contextual design principles and concludes with a meta-analytic analysis of how effective each of the five design principles actually worked.

\subsection{General method}

The experiments in this article used simple experimental protocols because extensive previous research indicated that more elaborate protocols were not necessary for factors such as scaling model [26, 38], representation of affective responses [26, 39], presentation venue [40], simulation medium [40], or demographic factors. For example, a review of demographic differences in environmental perception, covering over 19000 participants from 21 countries, 3821 scenes, and 12 demographic factors, indicated a very high consensus $(r>.82)$ across all demographic groups except for children less than 12 years old vs. adults, political groups such as special interest groups vs. non-special interest groups, and designers vs. non-designers for avant garde projects [41]. Thus, in this section, static color images were used because the meta-analyses given in Section 3 indicated that more elaborate media were not needed. Formal experimental designs and random sampling were used because they really are needed to obtain valid results $[7,42]$.

Five contextual design principles were tested in the four experiments that are described in this section. The principles were (a) the style of a new (infill) building, or whether it does or does not match the style of its surrounding buildings (the context); (b) Height of infill building as compared to the height of its context; (c) trees; (d) setbacks; and (e) distance from observer to infill building. The full reasons for selecting these particular principles are too extensive to list here, but the prima facie reasons are (a) the dominant criterion for contextual fit is matching existing buildings and the dominant distinction is 


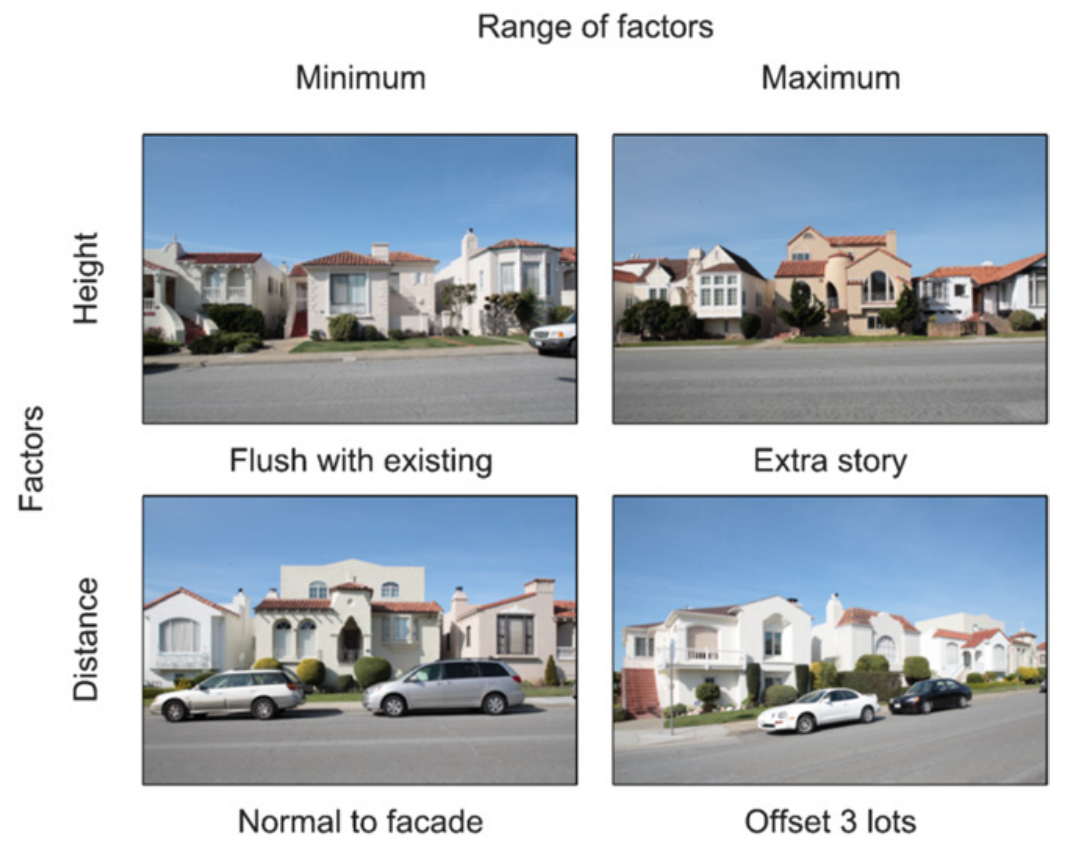

Figure 1. Factors and their minimum and maximum values in the Lakeshore experiment.

likely to be architectural style; (b) relative height is important because objections to new infill houses are likely to focus on increased size; (c) trees are important because a lot of people like them; (d) setbacks are important because they have been regulated since 2778 B.C. when the current state-ofthe-art in building construction dictated that pyramids have decreased footprints as the height of the pyramid increased, resulting in structures such as the Step Pyramid of Zoser [43]; and (e) distance from observer to infill building is important because it is another way to estimate how strongly simulation effects influence impressions of environments. Additional details on the empirical evidence regarding contextual design are given in [44, 45].

\subsection{Height and distance (Lakeshore)}

This experiment investigated the effects of height and distance from observer on judgments of visual appeal of a whole block of houses. Blocks were selected from the Lakeshore neighborhood of San Francisco, from which the name of this experiment was taken. A brief history of this neighborhood is given in [46]. Height was expressed as either the same as existing houses or with one extra story. Distance from observer was expressed as taking a photograph directly across the street, taking the photo off-set one lot, taking the photo off-set two lots, or taking the photo offset three lots. The main factors for this experiment were height (2) and distance (4). Two streets were sampled from a local neighborhood for each cell, generating an experimental design of height (2) by distance (4), by within (2), for a total of 16 stimuli. Figure 1 shows the ranges of each factor in this experiment.

\subsubsection{Data Acquisition}

Data were collected using the simple protocol of showing participants static color images and obtaining semantic differential ratings on the criterion of not appealing (1) to appealing (8). The required number of participants was calculated with power analysis. Power analysis indicated that at least 27 participants 
Usage, Usability, and Utility of 3D City Models

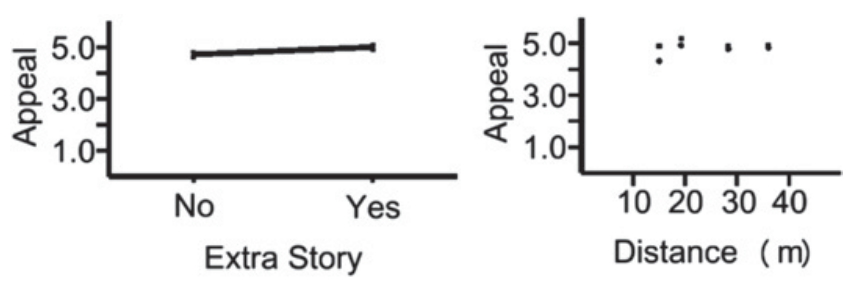

Lakeshore

Figure 2. Means for Lakeshore experiment. Solid lines indicate contrasts that were significant at the individual " $p<.05$ " level.

would be required. In the event, there were 37 undergraduate engineering students, with mean age of 20.1 years $(\mathrm{SD}=4.2)$. Thirty were male and seven were female. Political affiliations were 13 liberal, 13 moderate, 3 conservative, and 8 who did not state political affiliation.

\subsubsection{Results}

Overall effect sizes were $0.6 \%$ of variance for third story $(\mathrm{F}(1,540)=8.93, \alpha=.003)$ and $0.1 \%$ of variance for distance $(\mathrm{F}(1,540)=0.3 \%$ of variance, $\alpha=.12)$. mse was 1.12 . So, overall, addition of an extra story had a detectable effect on visual appeal of a whole block but distance to observer did not. But that does not tell the whole story.

The influence of an extra story could mean that an extra story diminished the overall visual appeal of the block, but it could also mean that the extra story increased the visual appeal of the whole block. This ambiguity can be resolved by reporting specific contrasts rather than overall "variances accounted for". Figure 2 shows the findings at this level of detail. For the factor of height, visual appeal of the block for three story houses was 4.98 and visual appeal of the block for two story houses was 4.72. This difference was statistically significant $(\mathrm{F}(1,540)=8.78, \alpha=.003)$. But the empirical results directly contradict the conventional wisdom that added height diminishes the visual appeal of a block. In this case, the three story houses were preferred over the two story houses. For distances, the relevant datum is the difference in perceived appeal between two and three story houses at different distances. The data are also shown in Figure 2. At 15 and $19.2 \mathrm{~m}$, there was a detectable difference in visual appeal between houses with an extra story and houses the heights of which matched the rest of the block. At 28.3 and $37 \mathrm{~m}$, adding that extra story had no detectable effect on visual appeal of the block.

Finally, the results can also be expressed in terms of correlations. All correlations in this article were calculated over the stimuli, so the $n$ ' $s$ are the numbers of stimuli. For the presence or absence of an extra story, the correlation with visual appeal of a whole block was $r=.39$, with the extra story being preferred. For the mitigation by distance of the effect of a third story, the correlation with visual appeal of the whole block was $r=.27$. This means the farther the distance to the new building, the better the block looked.

\subsection{Height, distance, and style (Mission Possible)}

In this experiment the range of distances was increased to $120 \mathrm{~m}$. The levels of distance were 7.5, 15, 30,60 , and $129 \mathrm{~m}$. It was not possible to find streets where all the houses within $120 \mathrm{~m}$ were of the same style, so computer simulations of streets were made. The style of the houses was two story Mission Revival. Houses were designed with random combinations of 5 design features: roof line (4 options), openings (4), colors (20), curtains (16), and stair location (left, right). There were 20 houses on each block. The infill buildings were of two styles that would be out of both scale and character with the two 


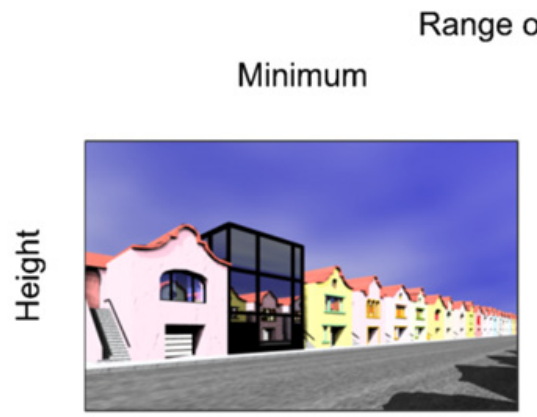

3 Stories

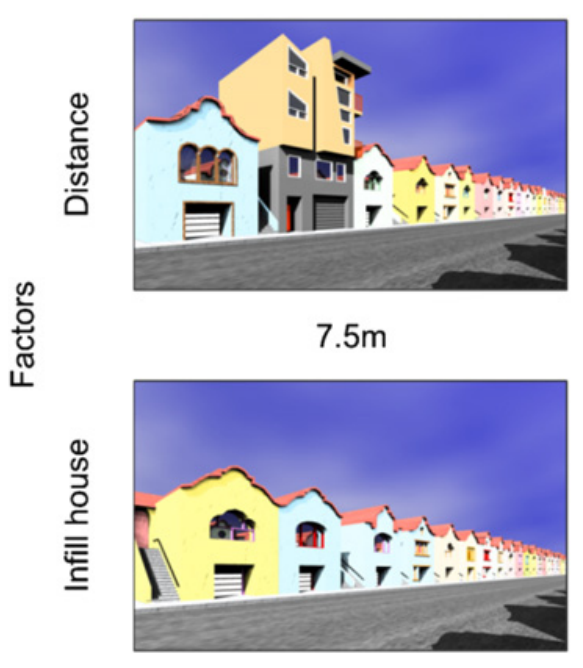

None

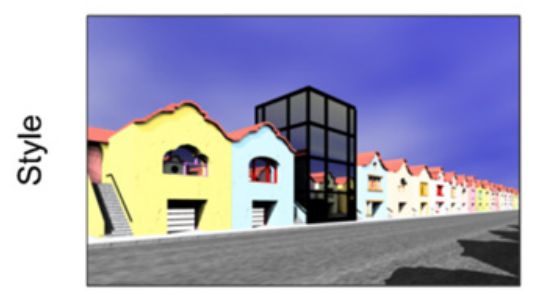

I Beam
Maximum

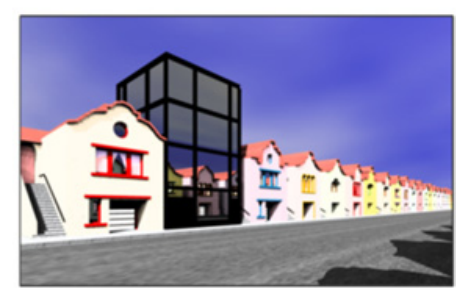

4 Stories

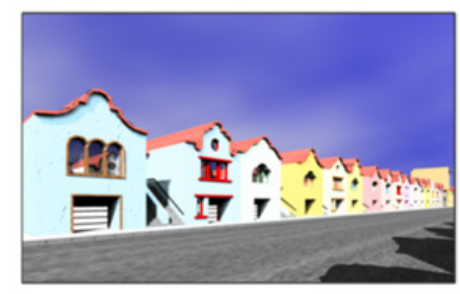

$120 \mathrm{~m}$

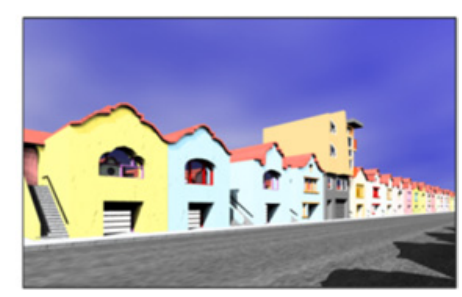

4 Story infill

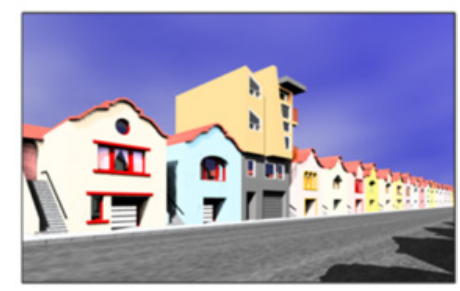

Ripley

Figure 3. Factors and their minimum and maximum values in the Mission Possible experiment.

story Mission Revivals: I Beam, which was adapted from van der Rohe's ITT campus, or the Extrude \& Rotate ("Twist \& Shout") avant garde motif made possible by contemporary computer drafting and manufacturing programs. Both infill styles were created in 3 and 4 story heights, or ratios of 1.5 and 2.0 above the existing conditions. The combination of distance, with 5 options, infill style, with two options, and infill height, with two options, produced an experimental design of distance (5) by infill style (2) $\mathrm{x}$ infill height (2), for a total of 20 scenes. In addition, four blocks were created with no infill buildings to serve as a control. Thus there were 24 scenes in this experiment. Figure 3 shows the factors and their ranges. 
Usage, Usability, and Utility of 3D City Models
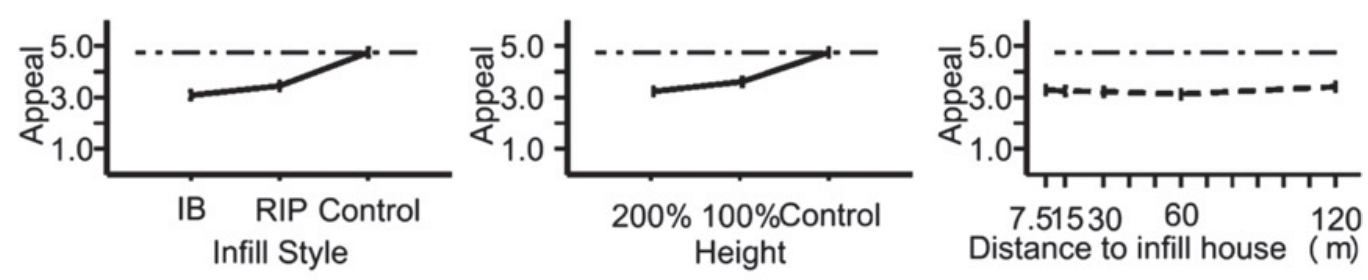

\section{Mission Possible}

Figure 4. Means for Mission Possible experiment. Solid lines indicate contrasts that were significant at the individual " $p<.05$ " level. Dashed lines indicate contrasts that were not significant at the individual " $p<.05$ " level. Lines with dots and dashes indicate the mean value of visual appeal for the control group (the blocks with no infill buildings).

\subsubsection{Data acquisition}

Power analysis indicated that 18 participants would be required. Accordingly, eighteen participants were recruited by a professional survey research firm from the adult population of a major city in the United States. Due to a technical malfunction, one participant's data were not usable. Demographics were otherwise balanced for sex and political affiliation. Ages ranged from 21 to 72 with a mean of 39 years and a standard deviation of 14 years. Occupations ranged from writer to marketing executive. The response was visual appeal over the range of not appealing (1) to appealing (8).

\subsubsection{Results}

Two analyses were done. The first analysis compared the visual appeal of blocks with no infill houses against the visual appeal of houses that did have an infill house. This contrast accounted for $8.3 \%$ of the variance in visual appeal $(\mathrm{F}(1,368)=46.87, \alpha=2 e-11)$. mse was 2.56 . Means were $\mathrm{m}_{\text {existing }}=4.72$ and $\mathrm{M}_{\text {infill }}=3.26$. The effect size for the contrast between existing and infill blocks was $r=.868$ on $n=24$ scenes.

The second analysis focused on the factors of infill style, infill height, and distance from observer to infill building. Height of infill building had the strongest overall influence on perceived appeal of a street $(1.3 \%$ of variance, $\mathrm{F}(1,320)=6.82, \alpha=.005)$. Style of infill building had a similar influence $(1.1 \%, \mathrm{~F}(1,320)=6.01, \alpha=.008)$. Distance had a much smaller influence $(0.07 \%, \mathrm{~F}(1,320)=0.36$, $\alpha=.55)$. mse was 1.82. Means for each factor are shown in Figure 4. Numerically, the means were as follows: $\mathrm{M}_{3 \text { stories }}=3.45, \mathrm{M}_{4 \text { stories }}=3.07, \mathrm{M}_{\mathrm{I} \text { Beam }}=3.08, \mathrm{M}_{\text {Ripley }}=3.39, \mathrm{M}_{7.5 \mathrm{~m}}=3.29, \mathrm{M}_{15 \mathrm{~m}}=$ $3.25, \mathrm{M}_{30 \mathrm{~m}}=3.22, \mathrm{M}_{60 \mathrm{~m}}=3.13$, and $\mathrm{M}_{120 \mathrm{~m}}=3.41$. In terms of correlations over 20 scenes, the effect sizes were $r=-.58$ for relative height, with a ratio of 1.5 being better than $2.0 ; r=.55$ for infill style, with avant garde being better than I Beam; and $r=.17$ for distance, which suggests that distance did mitigate the negative impact of infill houses but the effect of distance was small relative to the effects of the other factors. Means are shown in Figure 4.

\subsection{Third story additions (3 Story Sunset)}

The main topic of this experiment was how strongly setting back an extra story influenced the visual appeal of a street. Stimuli were streets in the Sunset District of San Francisco. This neighborhood was chosen because most of it was built by a single developer at one time and so has a high degree of stylistic 


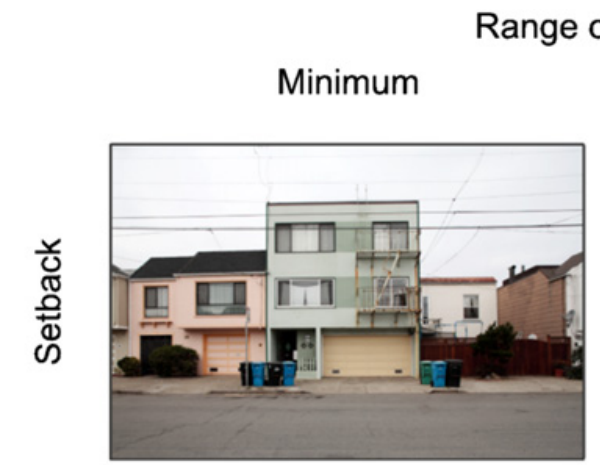

A. No

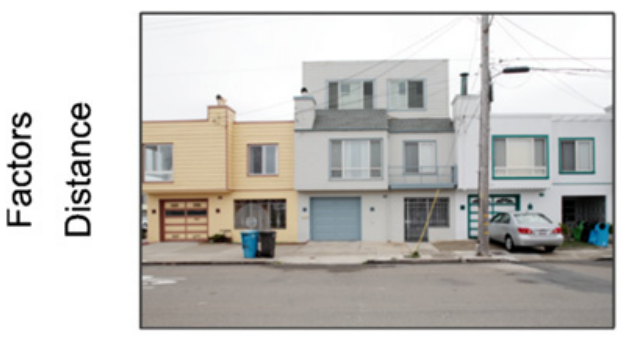

C. Normal to facade

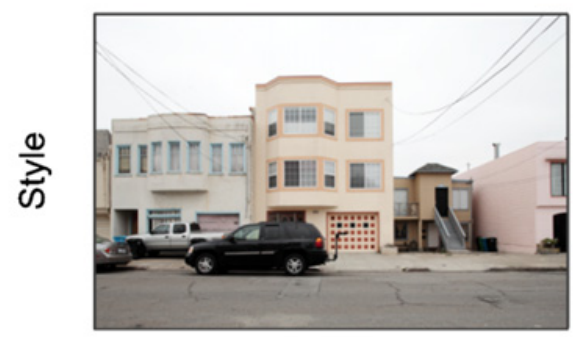

E. Richmond Special
Maximum

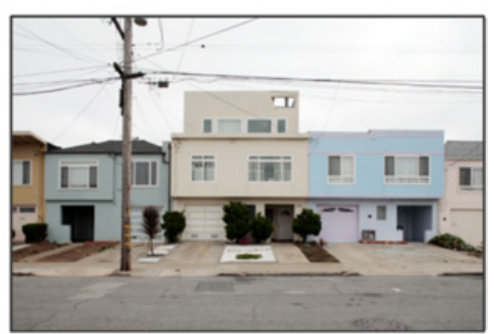

B. Yes

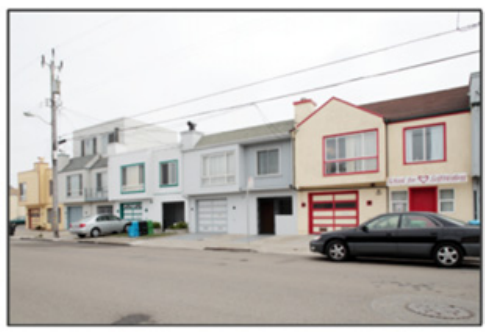

D. Offset 3 lots

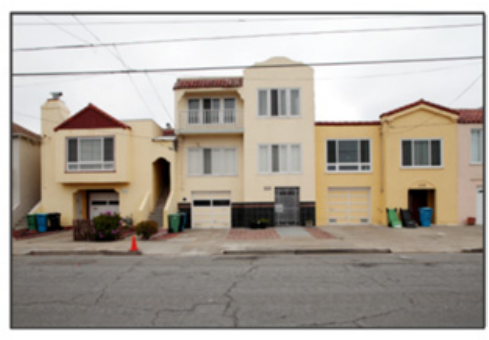

F. Pre-code

Figure 5. Factors and their minimum and maximum values in the 3 Story Sunset experiment.

homogeneity. For a history of this neighborhood, see [47]. However, over time, third stories were added, some with and some without third story setbacks, so the neighborhood was a suitable choice for a study on how setbacks influenced visual appeal. The experimental design was third story (yes or no) by distance $(0,1,2$, or 3 lots; 22.6, 25, 29, or $34.7 \mathrm{~m})$, by three examples within each cell, for a total of 24 stimuli. Figure 5 shows the factors and their ranges.

Because the sampling criterion did not include architectural styles, there were four different styles in the sample. The original style of this neighborhood was a two story box with one vertical partition and a shallow roof. This was the "Dolger" style. It was named after the developer who built thousands of these houses after World War II. Scene C in Figure 5 shows a Dolger with a third story addition. Subsequently the level of detail was reduced to flat boxes (Scene A in Figure 5). In response, the local planning department began recommending the addition of bay windows, resulting in a style called the "Richmond Special" (Scene E in Figure 5). Other stimuli that were built before style was regulated had unique styles (Scene F in Figure 5). 
Usage, Usability, and Utility of 3D City Models
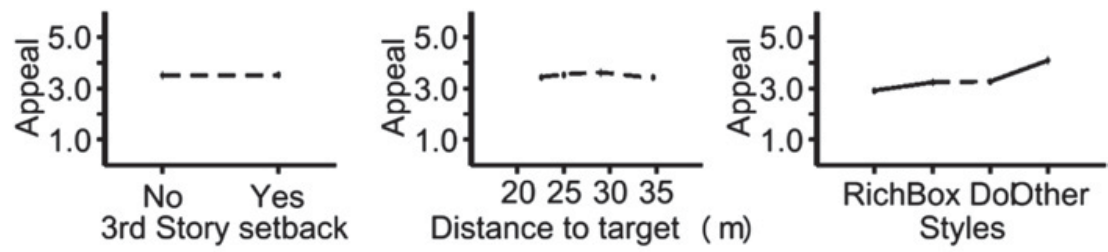

\section{Sunset}

Figure 6. Means for the 3 Story Sunset experiment. Solid lines indicate contrasts that were significant at the individual " $p<.05$ " level. Dashed lines indicate contrasts that were not significant at the individual " $p<.05$ " level.

\subsubsection{Data Acquisition}

Power analysis indicated that 19 participants would be required. Twenty-four participants were recruited by a professional survey research firm. There were equal numbers of men and women, and also equal numbers of political liberals, moderates, and conservatives. The mean and standard deviation of age were $\mathrm{M}=45.1$ and $\mathrm{SD}=13.5$ years. Occupations ranged from social worker to business owner. Responses were ratings of visual appeal ranging from not appealing (1) to appealing (8).

\subsubsection{Results}

The effect of setting back the third story accounted for $.02 \%$ of variance $(\mathrm{F}(1,575)=3.00, \alpha=$ $.08)$. Distance accounted for less than $.01 \%$ of variance $(\mathrm{F}(1,575)=0.01, \alpha=.92)$. mse $=1.25$. Post-hoc data inspection revealed that these participants reacted to the style of the infill building. Together, this classification of styles into Dolger, Flat Box, Richmond Special, and Other accounted for $7.1 \%$ of variance in visual appeal $(\mathrm{F}(3,525)=36.17, \alpha=2 \mathrm{e}-21)$. This effect was far larger than either third story setback or distance from observer. Means are shown in Figure 6. Numerically the means were $\mathrm{M}_{\text {other style }}=4.17, \mathrm{M}_{\text {Dolger }}=3.35, \mathrm{M}_{\text {Flat box }}=3.24 \mathrm{~m} \mathrm{M}$ Richmond Special $=2.92, \mathrm{M}_{\text {setback }}=$ $3.52, \mathrm{M}_{\text {no setback }}=3.51, \mathrm{M}_{15 \mathrm{~m}}=3.45, \mathrm{M}_{19.2 \mathrm{~m}}=3.55, \mathrm{M}_{21.3 \mathrm{~m}}=3.44$, and $\mathrm{M}_{27.3 \mathrm{~m}}=3.44$. In terms of correlations of visual appeal over scenes, the overall results were $r=.01$ for third story setback and $r=.008$ for distance, both on $n$ stim $=24$.

\subsection{Third story additions and trees (Tree Fix)}

In the Three Story Sunset experiment, there was the possibility that the factor of setback was confounded with the factor of infill style. That occurred because the sampling scheme was not designed to cross those two factors. Since obtaining a valid sample of existing blocks that did cross style and setback was infeasible to the point of being hopeless, the next experiment used simulated blocks for which the design features of interest could be crossed. In this study, three story houses were found that either did or did not have setbacks on the top level. Then the scenes were retouched to move the top story forward or back. In addition, trees were added in the expectation that, ceteris paribus, the positive value of street trees would fix the negative impacts of new infill projects.

Buildings were chosen using random sampling within the Noe Valley district of San Francisco. A history of that neighborhood is given in Yenne (2004). Random numbers were used to identify possible blocks and lots. If, upon site inspection, the designated house had three stories, and the third story was or was not set back about $5 \mathrm{~m}$, it was photographed. This process continued until there were 


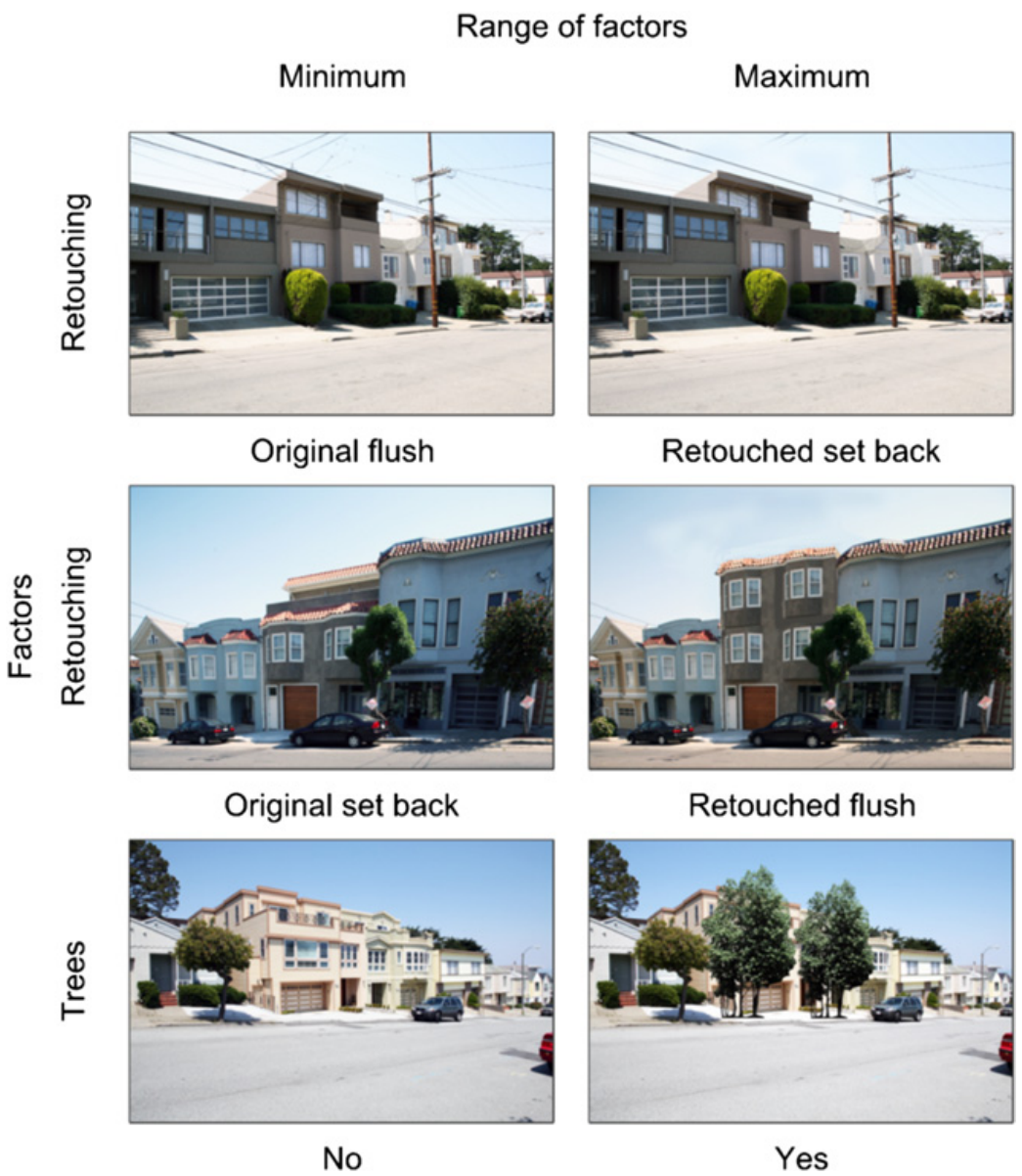

Figure 7. Factors and their minimum and maximum values in the Tree Fix experiment.

four original houses: two that had third stories flush with the lower two floors, and two that had third stories setback from the other floors. Then, each original image was retouched to either move the top floor back if it was originally flush or move it forward if it was originally setback. Trees were added as an additional feature, producing a factorial experimental design of setback (yes, no), by trees (yes, no) by retouched (yes, no), and a total therefore of 16 scenes. Figure 7 shows the factors and their ranges.

\subsubsection{Data Acquisition}

Power analysis indicated that at least 23 participants would be required. In the event, there were 29 undergraduate engineering students, with mean age of 20.1 years $(\mathrm{SD}=4.2)$. Twenty-six were male and three were female. Political affiliations were 11 liberal, 14 moderate, 2 conservative, and 2 who did not state political affiliation. Scenes were shown in a Power Point presentation during a class. Instructions were "Please look at some street scenes and rate each on a scale of Not appealing (1) to appealing (8). The first two scenes show the range of variation. Please do not rate the first two scenes". Then two warm-up scenes were shown, followed by the 16 scenes in the experimental design. 
Usage, Usability, and Utility of 3D City Models
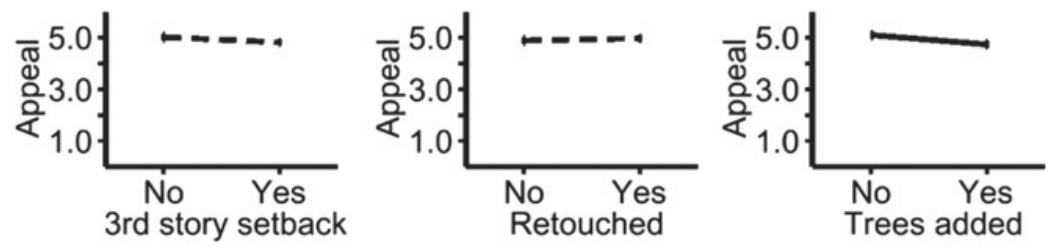

\section{Tree Fix}

Figure 8. Means for the Tree Fix experiment. Solid lines indicate contrasts that were significant at the individual " $p<.05$ " level. Dashed lines indicate contrasts that were not significant at the individual " $p<.05$ " level.

Table 5. Meta-analytic summary of contextual design principles.

\begin{tabular}{l|l|l|r|r|r|r|r|r}
\hline Factors & Reported* & Sources** & $\hat{r}$ & $\Sigma \mathrm{n}$ & $.05 \mathrm{ci}$ & $\mathrm{n}_{\text {over }}$ & $\chi^{2}$ & $\alpha$ \\
\hline \multirow{2}{*}{ Architectural Style } & Before & $6-14$ & .68 & 167 & $.59, .76$ & 4160 & 78.63 & $5 \mathrm{e}-14$ \\
\cline { 2 - 9 } & After & $6-15$ & .66 & 191 & $.57, .73$ & 5680 & 79.41 & $1 \mathrm{e}-13$ \\
\hline \multirow{2}{*}{ Trees } & Before & $21-27$ & .62 & 202 & $.53, .70$ & 5300 & 12.12 & .02 \\
\cline { 2 - 9 } & After & $21-28$ & .58 & 218 & $.48, .66$ & 5095 & 23.9 & $4 \mathrm{e}-4$ \\
\hline \multirow{2}{*}{ Height } & Before & $16-17$ & -.24 & 58 & $-.47, .01$ & -8 & 6.67 & .005 \\
\cline { 2 - 9 } & After & $16-19$ & -.56 & 106 & $-.68,-.41$ & 1027 & 15.43 & .06 \\
\hline \multirow{2}{*}{ Setbacks } & Before & None & 0.00 & 0 & N/A & N/A & N/A & N/A \\
\cline { 2 - 9 } & After & $20-22$ & -.18 & 64 & $-.41, .07$ & -50 & 1.90 & .11 \\
\hline \multirow{2}{*}{ Distance } & Before & $1-2$ & .07 & 43 & $-.23, .36$ & -751 & .09 & 1.00 \\
\cline { 2 - 8 } & After & $1-5$ & .12 & 115 & $-.06, .29$ & -148 & 1.02 & .24 \\
\hline
\end{tabular}

* Indicates whether collective findings were calculated on data reported before or after the original experiments in this article.

** Indicates rows in Table A.2. N/A means "not available".

\subsubsection{Results}

The presence of trees had the largest influence on visual appeal of the street $(\mathrm{F} 1.0 \%, \mathrm{~F}(1,420)=7.52$, $\alpha=.003)$. Setting back a third story had a much smaller effect $(\mathrm{F}(1,420)=2.52, \alpha=.07)$, and retouching had an even smaller effect $(\mathrm{F}(1,420)=0.49, \alpha=.44)$. The effect of photographic retouching had an even smaller effect $(0.07 \%$ of variance). Adding trees had a deleterious effect on visual appeal $\left(\mathrm{M}_{\mathrm{without} \text { trees }}=5.10, \mathrm{M}_{\mathrm{with} \text { trees }}=4.74, \mathrm{~F}(1,420)=7.52, \alpha=.005\right)$. Means for setbacks were $\mathrm{M}_{\text {without }}=5.02$ versus $\mathrm{M}_{\text {with }}=482$. The difference for setbacks was not detectable $(\mathrm{F}(1,420)=2.25$, $\alpha=.13)$. Likewise, the difference between the actual photographs and the retouched photographs was not detectable (M's of 4.97 and $4.89, \mathrm{~F}(1,420)=0.51, \alpha=.47$ ). The means are shown in Figure 8 .

In terms of correlations with visual appeal over $n=$ nstim $=16$ scenes, the effects of trees, setbacks, and retouching were, respectively, $r=-.25,-.14$, and .06. In terms of planning decisions, these data suggested that (a) in this case, adding trees had the unusual effect of decreasing visual appeal, (b) 
third story setbacks again had an undetectable effect on visual appeal, and (c) simulation effects, this time of retouching images, again had a very small effect on judgments of visual appeal of physical environments.

\subsection{Meta-analysis of findings on contextual design principles}

As was the case for scaling and simulation, the empirical data for contextual design principles can be presented in meta-analytic form. Table A.2 in the appendix lists experiments, including the four experiments presented in this article, for which correlations with visual appeal were reported. Table 5 shows the meta-analysis for five of the urban design principles. Lines labeled "before" list the collective body of knowledge before the four current experiments were done. Lines labeled "after" list the collective body of knowledge after the four current experiments were done. The changes between the "before" data and the "after" data also indicate this chapter's original contributions to the literature. The "after" collective correlation indicates, according to the current best standards of translating science into policy recommendations, the efficacies of the various design principles.

Interpretations of Table 5 follow the examples given in Sections 2 and 3. For the effect of architectural style of a new project, the style of that project has a strong effect on visual preferences for a whole block. But...there is a wide range of effects for this factor. The policy recommendation is to consider style as a valid contextual design principle, but test for effects of specific styles before implementation. For research, the new data presented in this chapter made an insignificant chance in the collective body of knowledge, so further research on this topic should focus on individual styles rather than on the overall claim.

For trees, the current policy recommendation is that, yes, trees do tend to improve visual appeal of streets. The difference in the collective body of knowledge on this topic was not changed much by the data reported in this chapter, but the heterogeneity did change. Previous findings were that trees had a beneficial effect; the current finding was that trees had a detrimental effect. Future research should thus focus on conditions in which trees have positive or negative effects. Inspection of the images in the Tree Fix experiment hint that the relative sizes of buildings and trees might be the critical factor.

The data for the effect of height of individual buildings on visual appeal of a street were statistically ambiguous before the results in this chapter were obtained. When those results are considered, the scientific data suggest that increasing the size of new houses from 1.5 to 2.0 times the heights of existing houses will decrease the visual appeal of blocks of houses. There is very little heterogeneity in these data and it would take an experiment with 1027 scenes to substantiate an empirical objection to this claim.

Distance effects continue to be small and heterogeneous. Findings obtained from experiments in real and simulated urban spaces replicate the findings from the meta-analysis of simulations: compared to physical factors of environments, simulation effects are minor. Considerations of efficacies of simulation media is therefore, probably not an efficient protocol for evaluating urban spaces.

\section{SUMMARY AND CONCLUSIONS}

In this chapter the concept of "efficiency" is formalized using the statistical method of meta-analysis. Meta-analysis is then used to evaluate the efficiencies of different simulation media. Simple static color images do at least as well as any other medium for evaluating visual appeal of environments. Metaanalysis of contextual design principles indicates that architectural style, height relative to existing buildings, and street trees have effects sufficiently strong to merit regulation; setting-back third stories or requiring elaborate simulations have effects not strong enough to justify regulation. 
Usage, Usability, and Utility of 3D City Models

\section{APPENDIX}

Table A.1. Sources for meta-analysis of stimulation media.

\begin{tabular}{|c|c|c|c|c|c|}
\hline Exp & Medium 1 & Medium 2 & $\mathrm{r}$ & $\mathrm{n}$ & Source \\
\hline 1 & Slides & Black \& white sketches & .68 & 48 & {$[48]$} \\
\hline 2 & Slides & Tinted sketches & .87 & 15 & {$[48]$} \\
\hline 3 & On-site & Slides & .40 & 15 & [49] \\
\hline 4 & Slides & Digitized slides & .92 & 48 & {$[50]$} \\
\hline 5 & Slides & Digitized slides & .91 & 58 & {$[50]$} \\
\hline 6 & Slides & Digitized slides & .81 & 80 & {$[50]$} \\
\hline 7 & $\begin{array}{l}\text { B\&W sketches, } \\
\text { light abstraction }\end{array}$ & $\begin{array}{l}\text { B\&W Sketches, } \\
\text { moderate abstraction }\end{array}$ & .79 & 5 & [51] \\
\hline 8 & $\begin{array}{l}\text { B\&W sketches, } \\
\text { high abstraction }\end{array}$ & $\begin{array}{l}\text { B\&W sketches, } \\
\text { low abstraction }\end{array}$ & -.50 & 5 & {$[51]$} \\
\hline 9 & $\begin{array}{l}\text { B\&W sketches, } \\
\text { moderate abstraction }\end{array}$ & $\begin{array}{l}\text { B\&W sketches, } \\
\text { low abstraction }\end{array}$ & .82 & 5 & {$[51]$} \\
\hline 10 & Slides & B\&W sketches & .71 & 8 & {$[52]$} \\
\hline 11 & Slides & Computer sketches & .43 & 8 & {$[52]$} \\
\hline 12 & B\&W sketches & Computer sketches & .85 & 8 & {$[52]$} \\
\hline 13 & On-site & $\begin{array}{l}\text { 1-2 paragraph verbal } \\
\text { descriptions }\end{array}$ & .83 & 20 & {$[53]$} \\
\hline 14 & On site & Model & .40 & 8 & {$[54]$} \\
\hline 15 & On-site & Color photo. & .80 & 8 & [54] \\
\hline 16 & On-site & B\&W photo. & .32 & 8 & [54] \\
\hline 17 & Model & Color photo. & -.32 & 8 & [54] \\
\hline 18 & Model & B\&W photo. & .11 & 8 & [54] \\
\hline 19 & Color photo & B\&W photo. & .10 & 5 & {$[54]$} \\
\hline 20 & Full size mock-up & Scale model & .89 & 8 & [55] \\
\hline 21 & On-site & Color photo. & .72 & 10 & {$[56]$} \\
\hline 22 & On-site & B\&W photo. & .69 & 10 & [56] \\
\hline 23 & Color photo & B\&W photo. & .59 & 10 & {$[56]$} \\
\hline 24 & 140 degree color photo & 63 degree color photo & .93 & 17 & [57] \\
\hline 25 & "Framed" color photo & "Unframed" color photos & .97 & 19 & {$[58]$} \\
\hline 26 & Slides & Digitized slides & .76 & 123 & [59] \\
\hline 27 & On-site & Still photos & 152 & .86 & {$[60]$} \\
\hline 28 & Working drawings & Pen-and-ink line drawings & .88 & 5 & [61] \\
\hline 29 & Photomontage & Model & .86 & 7 & {$[62]$} \\
\hline 30 & Photomontage & Line elevations & -.67 & 7 & {$[62]$} \\
\hline 31 & Model & Line elevations & -.42 & 6 & {$[62]$} \\
\hline 32 & On-site & Static Color & .86 & 205 & [27] \\
\hline 33 & On-site & Dynamic & .83 & 171 & [27] \\
\hline 34 & Static color & Dynamic & .82 & 135 & {$[27]$} \\
\hline
\end{tabular}




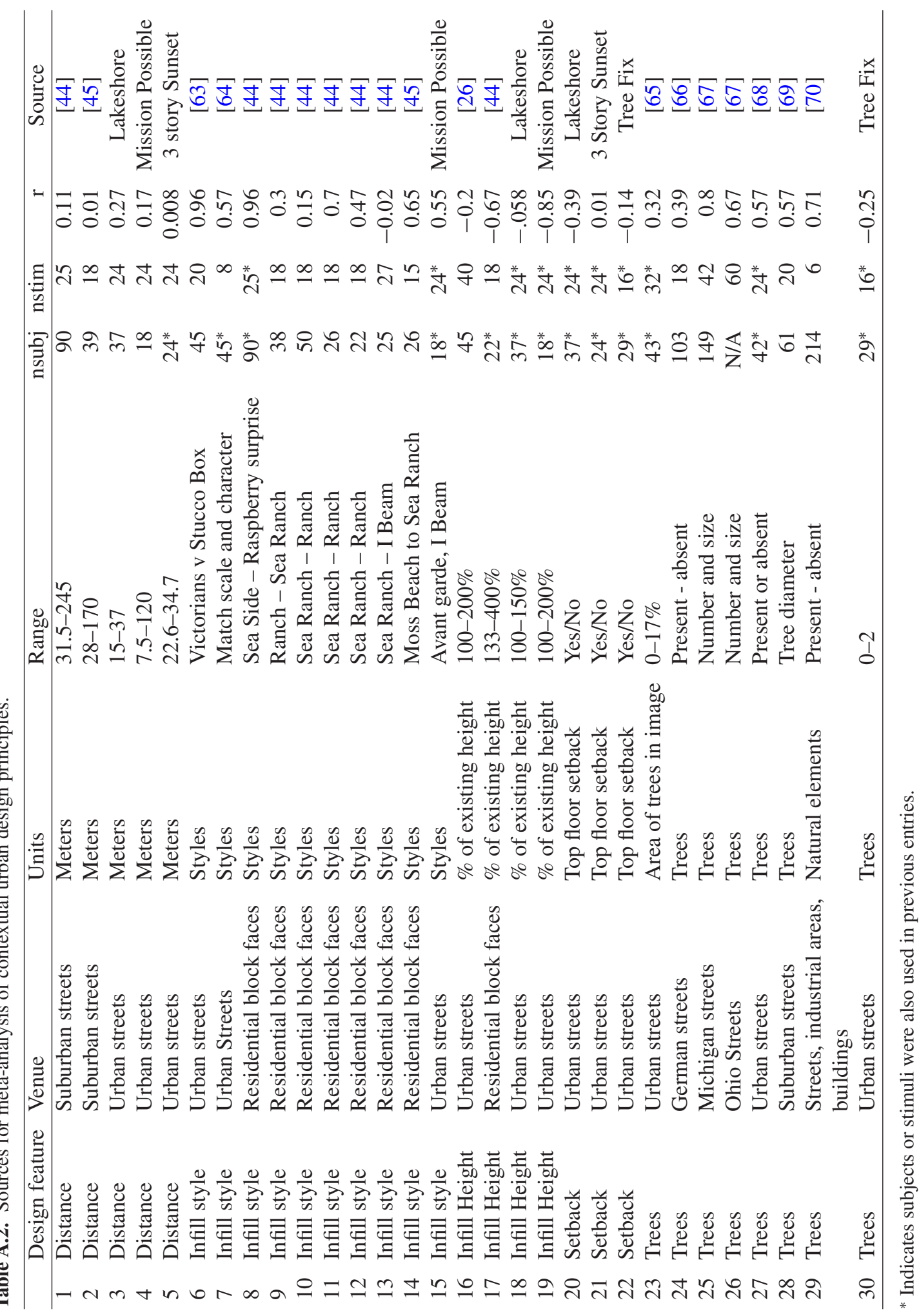


Usage, Usability, and Utility of 3D City Models

\section{References}

[1] J. M. Juran, Ed., A history of managing for quality: the evolution, trends, and future directions of managing for quality. Milwaukee: ASQC Quality Press, 1995.

[2] W. A. Shewhart, Statistical method from the viewpoint of quality control, 1986 ed. New York: Dover, 1939.

[3] J. M. Juran, Juran on quality by design: the new steps for planning quality into goods and services. New York: The Free Press, 1992.

[4] W. E. Deming, The new economics for industry, government, education. Cambridge, MA: Center for Advanced Engineering Study, MIT, 1994.

[5] D. H. Krantz, R. D. Luce, P. Suppes, and A. Tversky, Foundations of measurement vol. 1. Mineola, New York: Dover, 1971.

[6] W. E. Deming, Some theory of sampling. New York: Dover, 1950.

[7] R. A. Fisher, The design of experiments, 1971 ed. New York: Hafner, 1935.

[8] A. L. Cochrane, Effectiveness and efficiency: random reflections on health services, 2004 ed. London: Royal Society of Medicine Press, 1972.

[9] C. Collaboration. (2012, 13 July). Cochrane Reviews. Available: www.cochrane.org/cochrane-reviews

[10] K. Dickersin, "To reform U.S. health care, start with systematic reviews," Science, vol. 329, pp. 516-517, 2010.

[11] C. Collaboration. (2012, 13 July). About-us. Available: www.cochrane.org/about-us

[12] Cochrane Collaboration. (2005, August 21). Cochrane handbook for systematic reviews of interventions (4.2.5 ed.). Available: http://www.cochrane.org

[13] S. Nakagawa and I. C. Cuthill, "Effect size, confidence interval and statistical significance: a practical guide for biologists," Biological Review, vol. 82, pp. 591-605, 2007.

[14] G. V. Glass, "Primary, secondary, and meta-analysis of research," Educational Researcher, vol. 10, pp. 3-8, 1976.

[15] L. V. Hedges and I. Olkin, Statistical methods for meta-analysis. Orlando, Florida: Academic Press, 1985.

[16] E. H. Zube, D. G. Pitt, and T. V. Anderson, Perception and measurement of scenic resources in the Southern Connecticut river valley. Amhurst, MA: Institute for Man and His Environment, University of Massachusetts, 1974.

[17] S. Shuttleworth, "Consensus and the perception of landscape quality," Landscape Research, vol. 9, 1984.

[18] G. J. Buhyoff and L. K. Arndt, "Interval scaling of landscape preference by direct-and indirect measurement methods," Landscape Planning, vol. 8, pp. 257-267, 1981.

[19] H. W. Schroeder, "Environmental perception rating scales: a case for simple methods of analysis," Environment and Behavior, vol. 16, pp. 573-598, 1984.

[20] A. E. Stamps, "Meta-analysis in environmental research," in Space design and management for place making: proceedings of the 28th. annual conference of the Environmental Design Research Association, M. S. Amiel and J. C. Vischer, Eds., ed Montreal, Canada: Edmond, OK: Environmental Design Research Association, 1997, pp. 114-124.

[21] A. E. Stamps, "Advances in peer review research: an introduction," Science and Engineering Ethics, vol. 3 (1), pp. 3-10, 1997.

[22] A. E. Stamps, "Using a dialectical scientific brief in peer review," Science and Engineering Ethics, vol. 3, pp. 85-98, 1997.

[23] M. Mullins, "Interpretation of simulations in interactive VR environments: depth perception in Cave and panorama," Journal of Architectural and planning research, vol. 23, pp. 328-340, 2006.

[24] San Francisco Planning Department. (2010, 16 July 2010). Discretionary Review Reform.

[25] San Francisco Planning Department. (2003, 16 July 2010). Residential Design Guidelines. 
[26] A. E. Stamps, Psychology and the aesthetics of the built environment. Norwell, MA: Kluwer Academic, 2000.

[27] A. E. Stamps, "Use of static and dynamic media to simulate environments: a meta-analysis," Perceptual and Motor Skills, vol. 111, pp. 1-12, 2010.

[28] B. C. Lightner, "Survey of design review practices," American Planning Association, Chicago, Illinois, Planning Advisory Service MemoJanuary, 1993.

[29] D. L. Uzzell and E. M. Jones, "Incorporating the visual impact of buildings into BREEAM: a study for the Building Research Establishment," University of Surrey, Guilford, 1996.

[30] S. Loew, "Design control in France," Built Environment, vol. 20, pp. 88-103, 1994.

[31] G. Pantel, "Design control in German Planning," Built Environment, vol. 20, pp. 104-112, 1994.

[32] L. Nystrom, "Design control in planning: the Swedish case," Built Environment, vol. 20, pp. 113126, 1994.

[33] A. Vignozzi, "Design control in Italian planning," Built Environment, vol. 20, pp. 127-141, 1994.

[34] N. Nelissen and C. L. de Vocht, "Design control in the Netherlands," Built Environment, vol. 20, pp. 142-156, 1994.

[35] E. Calderon, "Design control in the Spanish planning system," Built Environment, vol. 20, pp. 157-168, 1994.

[36] U. Hohn, “Townscape preservation in Japanese urban planning," Town Planning Review, vol. 68, pp. 213-255, 1997.

[37] J. Punter and M. Carmona, The design dimension of planning: theory, content, and best practice for design policies. London: E\&F Spon, 1997.

[38] A. J. Oswald and S. Wu, "Objective confirmation of subjective measures of human well-being: evidence from the U.S.A.," Science, vol. 327, pp. 576-579, 2010.

[39] A. E. Stamps, "How distance mitigates perceived threat at 30-90m," Perceptual and Motor Skills, vol. 114, pp. 1-8, 2012.

[40] N. R. Feimer, "Environmental perception: the effects of media, evaluative context, and observer sample," Journal of Environmental Psychology, vol. 4, pp. 61-80, 1984.

[41] A. E. Stamps, "Demographic effects in environmental preferences: a meta-analysis," Journal of Planning Literature, vol. 14, pp. 155-175, 1999.

[42] R. A. Fisher, Statistical methods for research workers, 4th ed. ed. London: Oliver \& Boyd, 1932.

[43] B. Fletcher, A History of Architecture on the Comparative Method, 17 ed. New York: Charles Scribners' Sons, 1963.

[44] J. L. Nasar and A. E. Stamps, "Infill McMansions: style and the psychophysics of size," Journal of Environmental Psychology, vol. 29, pp. 110-123, 2009.

[45] A. E. Stamps, "Parameters of contextual fit: diversity, matching, individual style, responses," Journal of Urbanism, vol. 4, pp. 7-24, 2011.

[46] W. LaBounty (2009, 13 December 2011). The Gellert Brothers and Lakeshore Park. Available: http://www.outsidelands.org/lakeshore.php

[47] L. Ungaretti, San Francisco's Sunset District. Charlestown, South Carolina: Arcadia, 2003.

[48] J. H. Schomaker, "Measurements of preferences for proposed landscape modifications," Landscape Research, vol. 3, pp. 5-9, 1978.

[49] R. H. Gimblett, "Identifying the experimental qualities of landscapes: an exploration of artificial intelligence techniques," in Coming of age, EDRA 21.1990, 1990, pp. 196-203.

[50] J. Vining and B. Orland, "The video advantage: a comparison of two environmental representation techniques," Journal of Environmental Management, vol. 29, pp. 275-283, 1989.

[51] W. E. Tips and T. Savasdisara, "Landscape preference evaluation and sociocultural background: a comparison among Asian countries," Journal of Environmental Management, vol. 22, pp. 113124, 1986.

[52] K. Killeen and G. Buhyoff, "The relation of landscape preference to abstract topography," Journal of environmental management, vol. 17, pp. 381-392, 1983. 
[53] B. Shelby and R. Harris, "Comparing methods for determining visitor evaluations of ecological impacts: site visits, photographs, and written descriptions," Journal of leisure research, vol. 17, pp. 57-67, 1985.

[54] R. W. Seaton and J. B. Collins, "Validity and reliability of ratings of simulated buildings," in Environmental design: research and practice, W. S. Mitchell, Ed., ed Los Angeles: University of California Press, 1972.

[55] J. J. Lau, "Differences between full-size and scale-model rooms in assessment of lighting quality," in Architectural psychology: proceedings of the conference at Dalandjui, University of Strathclyde, 1969, 1970, pp. 43-48.

[56] R. B. Howard, F. G. Mlynarski, and G. C. Sauer, "A comparative analysis of affective responses to real and represented environments," in Environment and Cognition, W. Mitchell, Ed., ed New York: Seminar Press, 1972, pp. 6-6-6.

[57] J. I. Nassauer, "Framing the landscape in photographic simulation," Journal of environmental management, vol. 17, pp. 1-16, 1983.

[58] C. S. Law and E. H. Zube, "Effects of photographic composition on landscape perception," Landscape research, vol. 8, pp. 22-23, 1983.

[59] I. D. Bishop and R. N. Leahy, "Assessing the visual impact of development proposals: the validity of computer simulations," Landscape Journal, vol. 8, pp. 92-100, 1989.

[60] A. E. Stamps, "Use of photographs to simulate environments: a meta-analysis," Perceptual and Motor Skills, vol. 71, pp. 907-913, 1990.

[61] A. E. Stamps, "Comparing preferences of neighbors and a neighborhood design review board," Environment and Behavior, vol. 23, pp. 616-629, 1991.

[62] A. E. Stamps, "Use of comparative choice paradigm in governmental design review: a case study," Journal of Environmental Management, vol. 33, pp. 351-364, 1991.

[63] A. E. Stamps, "Simulation effects on environmental preference," Journal of Environmental Management, vol. 38, pp. 115-132, 1993.

[64] A. E. Stamps, "A study in scale and character: contextual effects on environmental preferences," Journal of Environmental Management, vol. 42, pp. 223-245, 1994.

[65] A. E. Stamps and S. D. Miller, "Advocacy membership, design guidelines, and predicting preferences for residential infill designs," Environment and Behavior, vol. 25, pp. 367-409, 1993.

[66] R. Weber, J. Schnier, and T. Jacobsen, "Aesthetics of streetscapes: influence of fundamental properties on aesthetic judgments of urban space," Perceptual and Motor Skills, vol. 106, pp. 128-146, 2008.

[67] H. W. Schroeder, G. J. Buhyoff, and W. M. Cannon, "Cross-validation of predictive models for esthetic quality of residential streets," Journal of Environmental Management, vol. 23, pp. 309316, 1986.

[68] A. E. Stamps, "Some streets of San Francisco: preference effects of trees, cars, wires, and buildings," Environment and Planning B: planning and design, vol. 24, pp. 81-93, 1997.

[69] J. N. Lien and G. J. Buhyoff, "Extension of visual quality models for urban forests," Journal of Environmental Management, vol. 22, pp. 245-254, 1986.

[70] B. Hernandez and M. C. Hidalgo, "Effect of urban vegetation on psychological restorativeness," Perceptual and Motor Skills, vol. 96, pp. 1025-1028, 2005. 